\section{PREPOSITIONS AND MINIMALIST CASE MARKING}

\section{INTRODUCTION}

Chomsky (1993:9) suggests that all structural Case marking be reformulated in Xbar theoretic terms, specifically under the Spec-Head relation. In this way, Nominative and Accusative Case assignment are reduced to Spec-Head agreement of NPs with an AgrS and an AgrO head, respectively. The immediate question that comes to mind is how the structural Case assigned by prepositions can be reduced to this format. Following van Riemsdijk (1990), I will argue that PPs have functional projections. In addition, I will show that $\mathrm{F}^{\circ}$ heads assign Case to NP complements of $\mathrm{P}^{\circ}$ which have raised to a right-branching Spec-FP position. I will show that the variety of complex prepositional constructions in Germanic and Romance languages (circumpositions, left-headed and right-headed "double"prepositions) can be reduced to a single right-branching FP-PP structure, offering evidence for minimalist assumptions about Case marking (checking) as a SpecHead relation.

\section{A FUNCTIONAL PROJECTION FOR PP}

As has often been suggested, some prepositions are very close to being pure Case markers. They include of as in the destruction of the house, and to which marks datives as in Karl gave a book to Fred. The status of these preposition-like elements as Case markers rather than prepositions is confirmed by the fact that they do not take the prepositional modifiers straight and right, which have been argued by Emonds (1986) to occur in the Specifier position of PPs. $\mathrm{P}^{\circ}$ modifiers such as right and straight cooccur only with bona fide prepositions such as at, out, after, towards, from, away, back, off, before, directional to, up and the like.

(1) a. Karl slowly gave the book (?*right) to Fred.

b. the destruction (*right) of the house

In itself, the presence of $\mathrm{P}^{\circ}$ modifiers is not a sufficient diagnostic for prepositionhood, since some prepositions cannot cooccur with the $\mathrm{P}^{\circ}$ modifiers right and straight. These include mostly nonlocative and nontemporal prepositions such as with, about, and by. The property which sets prepositions apart from Case markers such as of and to is the fact that they are associated with specific thematic roles (Comitative/Instrument for with, Theme for about). This is not the case for elements such as to and of, which take NPs with various thematic roles. In NPs such as the destruction of the house, the King of Sweden, the arrival of the children, the element of plays no role in selecting the complement of the head nouns destruction, king, and arrival. Similarly, although less obviously, to can introduce Patients (do damage to the house), Experiencers (It seems to me that ...), or Goals as in (1a). The element $b y$ introducing the by-phrase in a passive structure can be equally considered a Case marker, since it introduces Agents (The city was destroyed by the barbarians), Experiencers, (The destruction was felt by the citizens), Instruments (The city was hit by rockets) and Themes (This prediction is entailed by the hypothesis). The Case markers by, of and to can then be characterized by the fact that they do not exercise selectional or thematic restrictions on the NPs they introduce. This distinction between lexical prepositions and functional preposition-like Case markers is one that is found in many languages (see Kayne 1975 for French $\grave{a}$, Guerssel 1991 for Berber, Tremblay \& Kabhaj 1990 for Amharic).

The question now arises as to how these preposition-like Case markers are projected. Let us assume that e.g. (dative) to and (genitive) of head functional projections (FPs) rather than PPs. In a minimalist framework, there are at least two possible analyses for these structures. First, it might be that the head is to the left, and the NP moves at LF to a left-branching Spec-FP in order to check Case as in (2a) Another possible analysis is that the $\mathrm{F}^{\circ}$ is to the right, and that Case is overtly checked by movement to a right-branching Spec-FP and subsequent Spec-Head agreement as in (2b):
(2) a

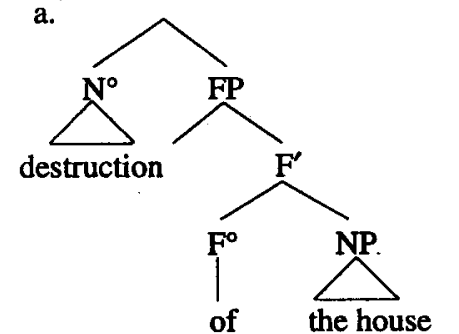

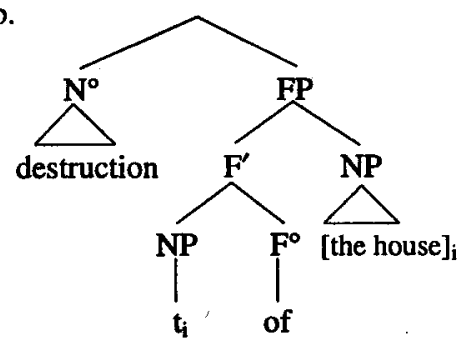

How do we choose between (2a) and (2b)? In this paper, I will argue that the rightbranching structure for preposition-like FPs as in (2b) allows for a number of generalizations that cannot be expressed under the left-branching structure (2a). The arguments in favor of this analysis come from complex prepositional constructions in English, French and Dutch. Complex prepositional constructions include circumpositions (from the top down), left-headed complex prepositions such as out of, into, onto, and right-headed complex prepositions such as down to, up to, away from. The presence of right-branching FPs in the domain of PPs allows us to reduce the apparent variety of complex prepositional constructions to a single underlying structure. 


\section{COMPLEX PREPOSITIONAL CONSTRUCTIONS}

\subsection{Circumpositions}

Van Riemsdijk (1990) argues for a right-branching structure in order to account for circumpositions in German:

(3) a. [Pp [PP unter der Brücke] durch ] under the bridge through

(=Van Riemsdijk 1990:(27a))

b. Decisions were communicated [(straight) from the top down]

c. Nice apartments can be found [(right) from the third floor up]

Van Riemsdijk (1990) analyzes durch 'through' as a "small" ${ }^{\circ}$, the equivalent of our $\mathrm{F}^{\circ}$ in (2b). In the minimalist approach to Case checking adopted here, we can assume that the NP moves to Spec-FP at LF to check its Case. 1 Similarly, Rouveret (1991) shows that Welsh inflected prepositions are the result of incorporation of pronouns into an agreement phrase.

(4) amdano

about-him

(= Rouveret 1991: $359(15)$ )

$\ldots\left[\mathrm{pp}\left[\mathrm{p} \mathrm{am}_{\mathrm{i}}[\mathrm{p}\right.\right.$ dano $\left.\left.]\right]\left[\mathrm{PP} \ldots[\mathrm{P} e]_{\mathrm{i}} \ldots\right]\right]$

The sentences $(3 \mathrm{~b}, \mathrm{c})$ show that circumpositional constructions also exist in English, although they seem to be constrained to adjunct positions, unlike in German and Dutch. ${ }^{2}$ Van Riemsdijk (1990) argues for the functional status of the second $\mathrm{P}^{\circ}$ in circumpositions such as (3) by showing that the apparent $\mathrm{P}^{\circ}$ durch 'through' does not exercise selectional restrictions on the NP. This is also true in (3c): the impossibility of *up/down the third floor shows that up and down do not select the preceding NP. We can conclude that $u p$ and down thus lose their usual status as $\mathrm{P}^{\circ} \mathrm{s}$ with a Path-meaning in order to function as $\mathrm{F}^{\circ} \mathrm{s}$ which do not impose selectional restrictions. Interestingly, $P$ modifiers cannot occur in front of the second preposition, unless the second preposition introduces an NP:

(5) a. Decisions were communicated from the top (*right) down.

b. Decisions were communicated from the top (right) down to the rank and file.

c. Nice apartments can be found from the third floor (*right) up.

d. Nice apartments can be found from the third floor (right) up to the tenth.
This contrast shows that the structure of $(5 a, c)$ cannot be reduced to that of $(5 b, d)$. Clearly, the second preposition in sentences (3) and (5a,c) does not select an empty NP. There is no reason why selection of an empty NP by a preposition should preclude the presence of a $\mathrm{P}$ modifier. Moreover, outside of the constructions under scrutiny, the prepositions up and down can occur without an NP while being modified by right or straight:

(6) Chico went right up/down.

The syntactic structure of the sentences ( 3 ) and $(5 a, c)$ then does not reduce to that of $(5 b, d)$. Rather, this structure must be analyzed exactly as the German construction in (3a). The PP final preposition is an $\mathrm{F}^{\circ}$, selecting the $\mathrm{PP}$ headed by the initial preposition. The PP in (7) can be represented in the same way as (3):

(7)

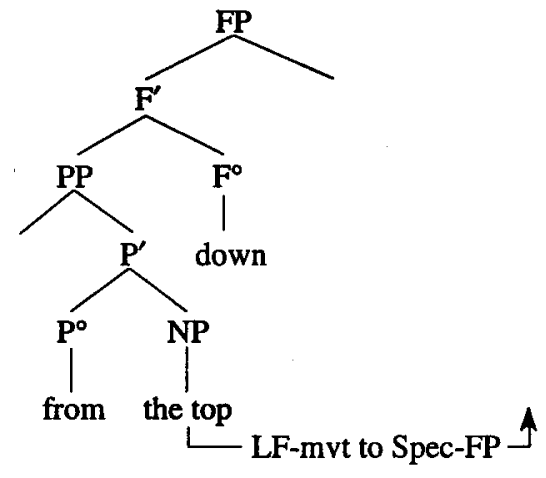

Since we assume that modifiers such as right and straight modify only $\mathrm{P}^{\circ} \mathrm{s}$, and not $\mathrm{F}^{\circ} \mathrm{s}$, the impossibility of these modifiers in $(5 \mathrm{a}, \mathrm{c})$ is accounted for ${ }^{3}$ Both the absence of prepositional modifiers on down and $u p$ in $(5 \mathrm{a}, \mathrm{c})$ and their lack of selectional restrictions on the preceding NP are evidence for their $\mathrm{F}^{\circ}$ status. Recall that these are the defining properties of $\mathrm{F}^{\circ} \mathrm{s}$ such as to and of discussed in section 1 . At LF, the NP selected by the $\mathrm{P}^{\circ}$ from moves to Spec-FP, which I argue is to the right of $\mathrm{F}^{\circ}$, in order to check Case by Spec-Head agreement in accordance with Minimalist Case theory. We can conclude that circumpositional constructions provide good evidence for the presence of right-branching functional projections in the domain of PP. In the remainder of this section, I will show that Van Riemsdijk's (1990) structure for circumpositions should be generalized to all PPs.

\subsection{Right-headed Complex Prepositions}

In addition to circumpositions, English also has complex prepositional constructions of the type (right) back/off/up/down to the border. These prepositional com- 
plexes can be provisionally described as right-headed since the second $\mathrm{P}^{\circ}$ in the complex selects the NP (* backlofflup/down the border). Traditionally, these constructions have been analyzed as cases in which the first $\mathrm{P}^{\circ}$ (back/offlup/down) selects the PP introduced by to (Jackendoff 1973: 348). I will first offer some criticism of this position before developing an account that relies on the general FP - PP structure (3)

Jackendoff (1973) argues that the prepositions out, in, up, down can select NP, PP or $\emptyset$. From can select only NP or PP, and away or back can select only PP and $\emptyset$, but not NP. In the case of PPs selected by Ps, Jackendoff shows that the two Ps must be part of the same constituent, because of the fact that Locative Inversion (cf. Hoekstra \& Mulder 1991 for a recent account) applies to the entire constituent, to subparts of it.

(8) a. Chico raced away from Mrs. Claypool. (= Jackendoff 1973: (16a))

b. Away from Mrs. Claypool raced Chico.

c. *? Away raced Chico from Mrs. Claypool.

Let us more closely examine the internal structure of this complex PP. ${ }^{4}$ For Jackendoff (1973), the preposition away selects the PP from Mrs Claypool. Hendrick (1976) points out that $P$ modifiers such as right, straight, can occur before both prepositions in this structure, but not in between these prepositions:

(9) a. Chico raced (right) away (*right) from Mrs. Claypool.

b. Sam disappeared (straight) down (*straight) into the darkness. (adapted from Hendrick 1976: (9ab))

The same is true in other cases of double prepositions, unless special intonation is introduced after the first preposition. Notice that the crucial $P$ modifiers can occur before the relevant prepositions if the first preposition is absent:

(10) a. Zeppo went up ( ${ }^{*}$ right) to the attic.

b. Zeppo went (right) up to the attic.

c. Zeppo went right to the attic.

(11) a. Harpo fell down (*right) from the top.

b. Harpo fell (right) down from the top.

c. Harpo fell right from the top.
(12) a. Groucho jumped back (*right) on the horse.

b. Groucho jumped (right) back on the horse.

c. Groucho jumped right on the horse.

Similar examples can be constructed with down from, down to, down at, down in, around to, down through, back on, back to, back from, out from, up from showing that the phenomenon is quite productive. Contra Jackendoff (1973), Hendrick (1976: 98) suggests that down and up can occur in Spec-PP position as can right and straight. When the $\mathrm{P}$ modifiers are generated in between prepositions, they would be competing with the first preposition for the same position in Spec-PP. Hendrick (1976) claims that the $P$ modifier which can occur before both prepositions in $(9$ 12) is generated to the left of the Spec-PP position. The problem with this analysis is that it is unclear how a preposition, an $\mathrm{X}^{\circ}$ category, can be generated in Spec-PP position, which is a position that allows only for XPs (Chomsky 1986). It could however be argued that these prepositions project to a larger PP of the type IPP Po pro ] which is generated in Spec-PP position in the following way:

(13)

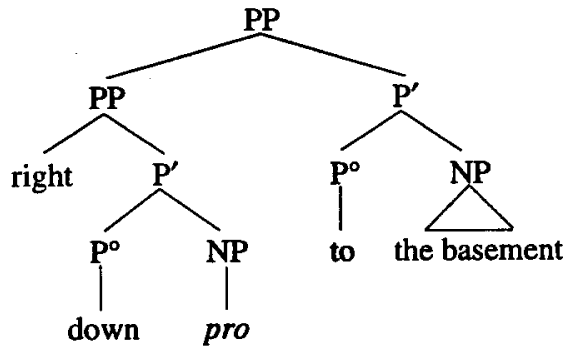

In this structure, the presence of pro as a complement of down would have to be independently justified. It is true that down can take overt NP complements indicating a Path. However, when the Path PP is fully expressed as in (14-15) below, there are two independent PPs which do not constitute a single constituent and can be independently modified by right or straight.

(14) a. Zeppo went (right) up the stairs (straight) to the attic.

b. Up the stairs went Zeppo to the attic.

(15) a. Harpo fell (straight) down the stairs (right) onto the table.

b. Down the stairs fell Harpo onto the table.

Note that the structure (13) does explain the absence of $P$ modifiers between both prepositions: the P-modifier of to competes with [down pro] for Spec-PP in (13). 
This approach entails that the first PP cannot be in Spec-PP of the second PP in (1415). Presumably, the first PP is an adjunct to the second PP, 5 allowing the Spec-PP of the second PP in (14-15) to be filled with P modifiers such as right, straight. This analysis however raises the question of why PPs with overt NP complements never seem to occur in Spec-PP, competing with P modifiers as represented in (13). In other words, why can the second $\mathrm{PP}$ always be modified by right and straight if the first PP carries an overt NP as in (14-15), but not if the first PP carries no overt NP as in (9-12)? The impossibility of $P$ modifiers between the two prepositions in $[\mathrm{P}-\mathrm{P}$ - NP] constructions attested in (9-12) therefore shows that these constructions cannot be reduced to structures of the type (14-15). 6 Since prepositions such as up and down can freely occur with and without NPs outside of [P - P - NP] constructions (Chico went up/Chico went up the stairs), proponents of a structure such as (13) would have to explain why the NP selected by the first preposition cannot be realized overtly, or why the presence of pro as a complement of down cooccurs with the absence of $\mathrm{P}^{\circ}$ modifiers on the second preposition.

What is the structure of $[P-P-N P]$ constructions if we are to maintain, with Jackendoff (1973), that these complex PPs constitute single constituents? Certainly we do not want to introduce a construction-specific constraint on the presence of $P$ modifiers. Rather, we would like to suggest that these $[P$ - P - NP] structures instantiate the structure (16), in which the $\mathrm{P}^{\circ}$ obligatorily incorporates into $\mathrm{F}^{\circ}$ by rightward adjunction. Alternatively, more closely following Chomsky (1993), one might say that the $\mathrm{F}^{\circ}-\mathrm{P}^{\circ}$ complex is generated in $\mathrm{P}^{\circ}$, and has to raise to $\mathrm{F}^{\circ}$ to check "strong" features. For the purposes of this paper, the differences between the "syntactic concatenation" approach and the "syntactic checking" approach are irrelevant. Under either, NP is overtly raised to Spec-FP position in order to check Case in a Spec-Head relation:
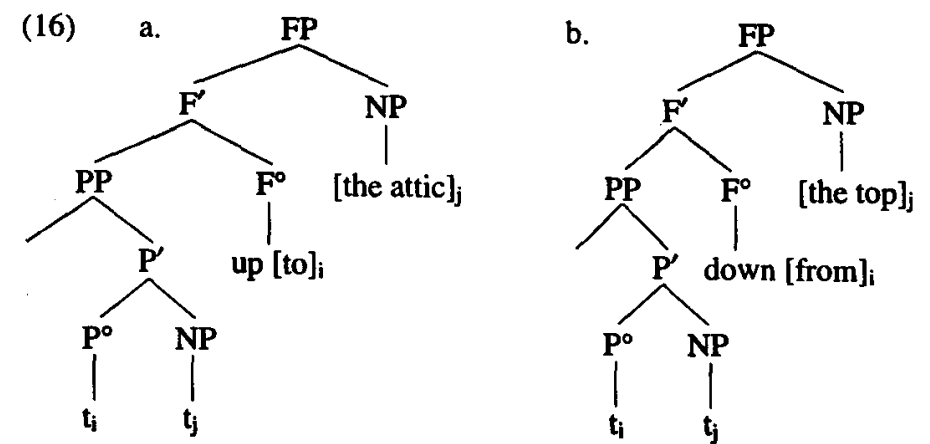

An overt $\mathrm{F}^{\circ}$ appears as a host for the incorporated preposition. As was the case for the final preposition in circumpositions, $\mathrm{F}^{\circ}$ is overtly realized by prepositions which are semantically compatible with the "true" $P^{\circ}$ selecting the NP. Under this analysis, Hendrick's (1976) observation that the $\mathrm{P}^{\circ}$ modifiers right and straight cannot appear in between the two prepositions in (9a-12a) is explained by the fact that the two prepositions constitute an incorporated syntactic unit.
The idea that the prepositions away, up, down, back spell out only $\mathrm{F}^{\circ}$ in this case is confirmed by the observation that the incorporating $\mathrm{F}^{\circ}$ does not exercise any thematic restrictions on the NP. When up and down head their own PPs, they are compatible only with NPs expressing a Path.7

(17) a. Zeppo went up the hill/*the attic.

b. Harpo fell down the stairs $/ *$ the top.

The examples (10-11) show that up and down do not exercise such a thematic restriction on the NP complement of the complex PP. Only to and from select the NP. The same difference in selectional restrictions between the two elements in a complex prepositional construction can be observed in (16). The incorporating $\mathrm{F}^{\circ} \mathrm{s}$ up and down in (16) add only a Path meaning to the complex PP, but without exercising selectional restrictions on the NP. Recall Van Riemsdijk (1990) also argues that the second $\mathrm{P}^{\circ}$ in circumpositions such as (3-4) is an $\mathrm{F}^{\circ}\left(\right.$ his $\left.\mathrm{p}^{\circ}\right)$ based on the absence of selectional restrictions by this apparent $\mathrm{P}^{\circ}$.

The absence of thematic selectional restrictions is of course a property that distinguishes functional categories from lexical categories. Functional heads in the PP domain are simply "semantically downgraded" prepositions: $\mathrm{F}^{\circ} \mathrm{s}$ do not exercise selectional restrictions on the NP selected by $P$, and cannot be modified by prepositional modifiers such as straight, right. (cf. also fn. 4). The status of "semantically downgraded" prepositions as $\mathrm{F}^{\circ} \mathrm{s}$ is not surprising. In fact, there is a parallelism here with the functional categories in the VP domain. It is well known that the English modals can, will, must diachronically were verbs before "grammaticalizing" as functional categories. In the domain of PP, functional categories are expressed by morphemes which are best described as "grammaticalized" prepositions with "weakened" prepositional properties. 8

Finally, the structure (16) can be radically extended to all PPs. We want to propose that run-of-the-mill PPs are always accompanied by an FP whose $\mathrm{F}^{\circ}$ head remains empty. The preposition then incorporates into this empty $F^{\circ}$.

\section{(18) a. (right) to the top}

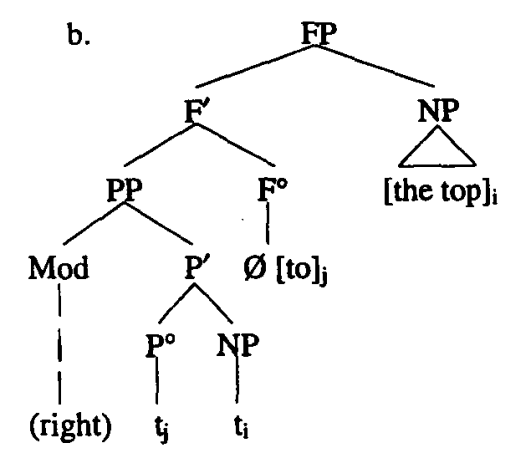


Importantly, the NP selected by $\mathrm{P}^{\circ}$ overtly moves to Spec-FP to check Case by Spec-Head agreement, in accordance with minimalist Case theory. We can conclude that an empty $\mathrm{F}^{\circ}$ always incorporates the lower preposition, and that this empty $\mathrm{F}^{\circ}$ can be spelled out by preposition-like $\mathrm{F}^{\circ} \mathrm{s}$ such as down, up, back etc. which are semantically compatible with the strongly lexical selecting preposition.9 At this point the question arises as to why movement to Spec-CP is overt here, while it is covert in the case of circumpositions as in (7). In other words, why is Procrastinate observed in circumpositions such as (7), but not in (18)? We will offer an answer to this question in section 3 .

\subsection{Left-headed Complex Prepositions}

Although circumpositions and right-headed complex prepositions show that there are right-branching FPs in the domain of PP, they do not directly provide evidence for the right-branching structure of the Case marker of in (2b) and to in (1). Direct evidence for this structure comes from a construction where of cooccurs with a "true" preposition such as out. From a descriptive point of view, complex $\mathrm{P}^{\circ} \mathrm{s}$ such as out of can be called "left-headed" because the first $\mathrm{P}^{\circ}$ is clearly the selecting preposition in the complex. Syntactically, a PP such as out of the house can in principle receive two structural analyses analogous to $(2 \mathrm{a}, \mathrm{b})$ :
(19) a.

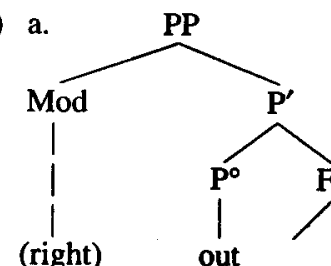

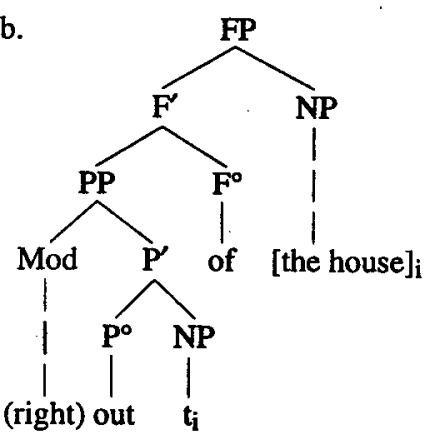

b.<smiles>PP</smiles>

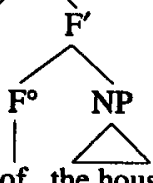

of the house (right) out
Note that in (19b) the PP out of the house corresponds to the structure of circumpositions proposed by Van Riemsdijk (1990). Regardless, there are two arguments in favor of the structure (19b), hence (2b). First of all, if of is an $\mathrm{F}^{\circ}$ heading a functional projection, it is more natural to assume that this functional projection selects the lexical PP projection in the same way $\mathrm{D}^{\circ}$ selects an NP and $I^{\circ}$ a VP. ${ }^{10}$ If PP were to select an FP as a complement, it would be the only lexical category to select its functional projection rather than being selected by it.

Secondly, the structure (19b), but not (19a), explains the contrast between (20a) and $(20 \mathrm{c}):{ }^{11}$
(20) a. This is the house [of which $]_{i}$ I saw [the destruction $t_{i}$ ].

b. They kicked John out of the house.

c. * This is the house [of which] $]_{i}$ they kicked John [out $\left.t_{i}\right]_{\text {. }}$

Under the analysis (19a), of which in (20c) is a constituent. As such, it should be subject to movement in the same way as the FP constituent of which in (20a). Under an analysis such as (19b), however, the ungrammaticality of (20c) can be explained by the fact that of which does not constitute a constituent. Since of branches to the right as an FP of PP, we may safely assume that it also does so as an NP Case marker.

In (19b), the preposition out does not incorporate into of. If incorporation of $\mathrm{P}^{\circ} \mathrm{s}$ in English is to involve uniformly rightward adjunction as we have argued in the preceding section, out in out of the country cannot have incorporated into of, because rightward adjunction should yield the ungrammatical order *of out the country.

This analysis can now be extended to the complex prepositions into and onto: 12
(21) a.<smiles>CC=C(C)C</smiles><smiles>C[In]</smiles>
Mod

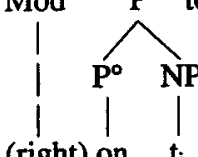

(right) on $t_{i}$

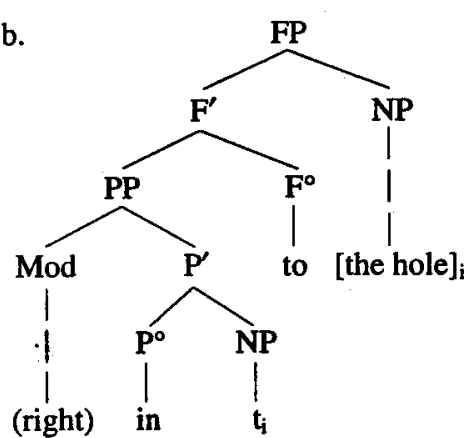

In these cases, the $\mathrm{F}^{\circ}$ to does not exercise the selectional restrictions it has as an independent preposition. As a $\mathrm{P}^{\circ}$, to can select NPs expressing a single spatial dimension as in Sue went to the border. In the same way as the $\mathrm{P}^{\circ} \mathrm{s}$ in and on, the complex $\mathrm{P}^{\circ} \mathrm{s}$ into and onto select NPs which have at least two dimensions: in/into the hole, on/onto the table. When the PPs $(5 \mathrm{a}, \mathrm{b})$ are compared to the PPs on the table/ in the hole, it is clear that only in and on can refer to both stative and directional locations whereas into and onto are only directional: the food is on $\left(*_{t o}\right.$ ) the tablelhe put the food on (to) the table. The $\mathrm{F}^{\circ}$ to then can be considered a spell-out of an $\mathrm{F}^{\circ}$ with directional meaning specifying the direction "preceding" the end Location ex pressed by the $\mathrm{P}^{\circ} \mathrm{s}$ in and $\mathrm{on}$. This strongly resembles the function of dative to in sentences such as (1a), where it acts as a directional modifier of the end Location, more precisely the NP carrying the Goal thematic role. The analysis presented here now allows for a strong correlation between the non-incorporating property of to and of in the domain of PP and their function as Case markers in the domain of NP: only non-incorporating $\mathrm{F}^{\circ} \mathrm{s}$ can select both PP and NP in English. The $\mathrm{F}^{\circ} \mathrm{s}$ of in out of, 
inside of and to in into, onto then function in the same way as the free $\mathrm{T}^{\circ}$ morphemes can, will, may in the domain of IP: they do not incorporate the lower lexical $\mathrm{X}^{\circ}$.

In other languages, there are also constructions in which it can be argued that a non-incorporating Case (FP) projection selects a PP. Vergnaud (1974) and Kayne (1975) give convincing arguments that French $d e$ 'of' and $\grave{a}$ 'to' are Case assigners (respectively genitive and dative) on NPs rather than prepositions (see also Zaring 1991). It is therefore likely that they also function as heads of FPs in complex prepositions such as the following, which can be given the same structure as $(3 \mathrm{~b}): 13$

(22) a. (juste) au-dessus de la table (right) over of the table (right) above the table

b. (juste) autour/en-dessous de la table (right) around/under of the table

c.

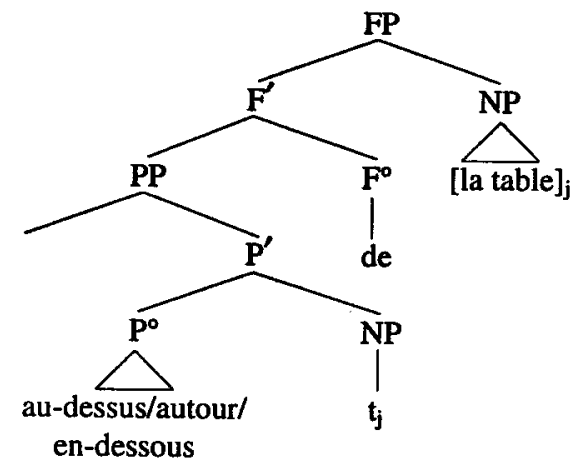

In French, the $\mathrm{F}^{\circ} \mathrm{de}$ 'of' which appears in left-headed complex prepositions also appears in right-headed complex prepositions of the type discussed in section 2.2 . The $\mathrm{F}^{\circ}$ de 'of' appears in the alternation [P - NP]/[de $\left.\mathrm{P}\right]$ which is illustrated in $(23 a, b)$. In the framework adopted here, this alternation can now be viewed as a syntactic one. Both sentences involve incorporation of the preposition into $\mathrm{F}^{\circ}$, and overt movement of an NP to Spec-FP for Case checking purposes, as illustrated in (23d,e). The implicit $\mathrm{F}^{\circ}$ Case marker must be overtly expressed if no overt NP is present in the PP, as illustrated in $(23 \mathrm{~b}, \mathrm{c})$.

(23) a. Je l'ai mis [sur/sous/dans l'armoire] I have put it on/under/in the cabinet.

b. Je l'ai mis [ dessus/dessous/dedans] I have put it [of-on/of-under/of-in (it)] c. Je l'ai mis [ là-dessus /là-dessous/là-dedans]

I have put it [there of-on/there of-under/there of-in]
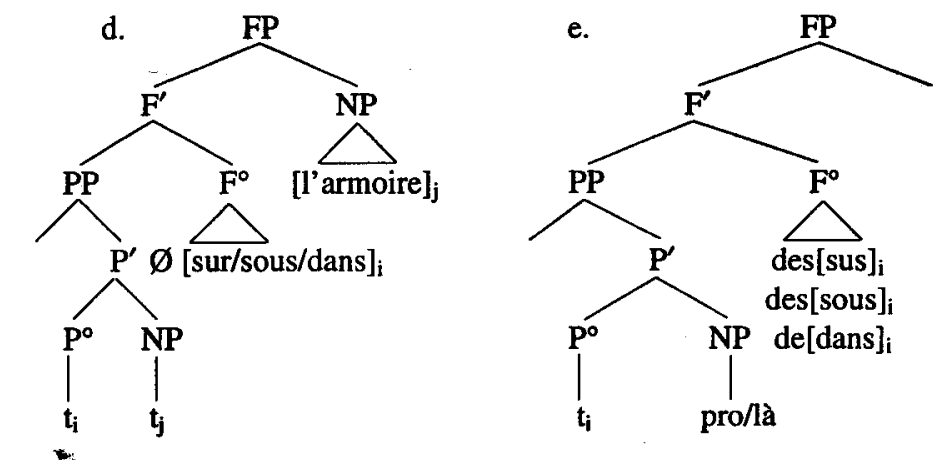

For (23b), Zribi-Hertz (1984) has convincingly shown that the empty NP corresponds to pro. Sportiche (1990: 72) argues that là 'there' and $i c i$ 'here', which can appear before dessus 'on', dessous 'under' and dedans 'in' in (23c), are locative NPs rather than PPs. ${ }^{14} \mathrm{We}$ can thus assume that there is allomorphy between an unexpressed $\mathrm{F}^{\circ}$ and an expressed incorporating $\mathrm{F}^{\circ}$ : overt movement of an NP to Spec-FP triggers a nonovert $\mathrm{F}^{\circ}$, lack of an overt NP in Spec-FP causes $\mathrm{F}^{\circ}$ to be spelled out as $d e$ 'of'. This kind of allomorphy between a Spec and its head in a functional projection can be likened to the "doubly filled COMP" effects encountered in the domain of CP. ${ }^{15}$ I suggest that an empty pro, la 'there' and ici 'here' can check their Case at LF, while all other NPs need to check Case overtly. The structure (23e) represents the visible syntax of both (23b) and (23c) before LF movement of pro and la.

The structure (23d), in which the preposition is incorporated into an empty $\mathrm{F}^{\circ}$, is justified by exceptions to the allomorphy: the empty $\mathrm{F}^{\circ}$ in (23d) can sometimes be overtly realized as de 'of' despite the presence of an overt NP. The examples quoted by Haase (1914: 339ff) show that in 17th century French, structures such as dedans nos murs 'within our walls' and dessus la table 'on the table' were possible, with both the $F^{\circ}-P^{\circ}$ complex and an NP in Spec-FP overtly realized (see also fn. 14 on Prince Edward Island French)

A comparison of sentence (22) with the sentences (23d,e) also shows that the prepositions au-dessus 'above', autour 'around' and en-dessous 'under' have not incorporated into the $\mathrm{F}^{\circ}$ de 'of'. In (23e), incorporation by adjunction is to the right of $d e$ 'of'. We can assume incorporation into $\mathrm{F}^{\circ}$ to be uniformly rightward in the domain of PP in French. If the prepositions in (22) were incorporated into $\mathrm{F}^{\circ}$, we would expect de 'of' to precede au-dessus 'above', autour 'around' and en-dessous 'under', contrary to fact. Therefore, we can conclude that these prepositions are in their base positions as is out in (19b).

As the analysis stands, there is no way of determining whether pro in $(23 \mathrm{~b}, \mathrm{e})$ is really in its base position, or whether it has moved overtly: pro is empty, and hence 
its movement cannot be verified directly. The only indication we have is the fact that the allomorphs dessus 'on', dessous 'under' and dedans 'in' appear both with pro and the NPs $i c i$ 'here' and $l d$ 'there'. The fact that the empty pro in (23e) is indeed in its base position can be independently confirmed by the null NP counterparts of structures such as (24):

(24) a. Je l'ai placé [FP [PP au-dessus/en-dessous/autour pro] [Fo $\emptyset] \_$] I placed it above/under/around

b. * Je l'ai placé [FP [PP au-dessus/en-dessous/autour] [ $\mathrm{F}^{\circ}$ de] pro ]

If the empty pro in (24) had moved overtly to Spec-FP, we would expect the $\mathrm{F}^{\circ}$ Case marker de 'of' to be spelled out in the same way as in (23b). The ungrammaticality of (24b) shows that Case cannot be spelled out when $\mathrm{P}^{\circ}$ has no overt NP complement and remains in situ. An analysis maintaining that pro is in Spec-FP in $(23 \mathrm{~b}, \mathrm{e})$ and (24) would have to formulate a rather cumbersome allomorphy stipulating that $d e$ 'of' must be spelled out either when an overt NP is in Spec-FP of an $\mathrm{F}^{\circ}$ which has not incorporated a $\mathrm{P}^{\circ}(22)$, or when $\mathrm{P}^{\circ}$ incorporates into $\mathrm{F}^{\circ}$ with an empty pro $\mathrm{NP}$ in Spec-FP $(23 \mathrm{~b}, \mathrm{e})$. By contrast, the analysis advocated here, by claiming that pro remains in situ, must state only that $d e$ 'of' is spelled out whenever either the NP complement of $\mathrm{P}^{\circ}(22)$ or $\mathrm{P}^{\circ}$ itself $(23 \mathrm{~b}, \mathrm{c}, \mathrm{e})$ raises to the FP projection. The $\mathrm{F}^{\circ}$ de 'of' is not spelled out when both $\mathrm{P}^{\circ}$ and NP raise at the same time (23a,d)). It is clear that the simpler alternative, without special stipulations as to the overt or covert character of NP in PPs, is preferable. Therefore, the structures in (24) provide additional evidence for the idea that pro remains in its base position in French PPs.

Another reason for syntactically treating pro, ici 'here', and la 'there' in the same way in (23) concerns their interpretation. Ici 'here' and là 'there' are deictic nominals which contrast with other deictic nouns such as celui-ci 'this one' or ca 'that' in that they have no (or rather, underdetermined values for) person, number, and gender features. The same is true for pro: in (23b) and (24a), the PP has a deictic interpretation, and it can be safely argued that pro also has underdetermined values for person, number, and gender features (cf. Kayne 1989, Vanden Wyngaerd 1994 Rooryck 1994 for the notion of underdetermined $\phi$-features). Assuming that pro is in the same position as la 'there' in (23) then allows for the generalization that only NPs with precisely these features do not overtly check Case in Spec-FP, but only raise to this position at $\mathrm{LF}$.

\subsection{FP - $P P$ vs. $P P$ - PP}

Our analysis of complex prepositional constructions makes a prediction with respect to multiple prepositions in general. We have just seen that $\mathrm{F}^{\circ}$ heads in constructions such as out of, into, au-dessus de 'on top of' do not incorporate the prepositional head they govern. When following another preposition, the constituent introduced by out of, into, au-dessus de 'on top of' is necessarily an FP, not a PP. Since the $\mathrm{F}^{\circ}$ head of out of does not incorporate, we predict that no element of out of incorporates by rightward adjunction into the preposition selecting the FP. The occurrence of $\mathbf{P}$ modifiers seems to corroborate this analysis:

(25) a. The horses came running from (right) out of the barn.

b. Back out from (right) inside of the hole squirmed Groucho. (adapted from Jackendoff 1973: (25))

In (25), the preposition from selects an FP headed by of. The prepositional modifier right modifies the PP selected by of.

Similarly, our analysis predicts that out of and inside of should not be allowed to function as a spellout for $F^{\circ}$. Since they do not jointly constitute $a P$, they cannot spell out an $\mathrm{F}^{\circ}$.

(26) a. Groucho came* out of behind/out from behind the curtain.

b. Groucho came * inside of from/from inside of the hole.

However, without of, the preposition out can spell out $\mathrm{F}^{\circ} \mathrm{s}$, and incorporate a "true" preposition it selects.

(27) The wolves roamed (right) out (*right) in the open.

In the case of multiple "true" prepositions, it is predicted that the two lowes prepositions can constitute an incorporated $\mathrm{F}^{\circ}-\mathrm{P}^{\circ}$ set, as in (27). The presence of $\mathrm{P}^{\circ}$ modifiers in $(29 \mathrm{a}, \mathrm{b}, \mathrm{c})$ shows that out and from head their own PPs, with from selecting the FP headed by down. There is no reason to assume the existence of multiple $\mathrm{F}^{\circ} \mathrm{s}$ successively incorporating $\mathrm{P}^{\circ}$.

(28) a. Straight down from right up above the altar groaned a mysterious voice. (adapted from Jackendoff 1973: (24b))

b. *? Down straight from right up above the altar groaned a mysterious voice.

c. ? Straight down from up right above the altar groaned a mysterious voice.

(29) a. The worm crawled right out from down under the lid.

b. The worm crawled out right from down under the lid.

c. The worm crawled out from right down under the lid. 
d. * The worm crawled out from down right under the lid.

Of course, the $\mathrm{F}^{\circ}$ down selecting the PP introduced by under can also remain implicit:

\section{(30) The worm crawled out from under the lid.}

In this case, under incorporates into an empty $\mathrm{F}^{\circ}$ whose FP is selected by the preposition from.

The question now arises as to what determines the difference between the circumpositions in (3) ([FP [PP from the top] down $\left.\mathrm{F}^{\circ}\right]$ ), where no incorporation nor overt NP movement to Spec-FP have taken place, and sentences such as (16b) ([FP[PP $\left.\left.\left.t_{j} t_{i}\right]\left[F^{\circ}\left[\text { down] from } \mathrm{j}^{\circ}\right] \text { [the top }\right]_{i}\right]\right)$ in which overt incorporation and overt NP movement to Spec-FP have taken place? In both cases, the $\mathrm{F}^{\circ}$ is spelled out by down. The PP constructions in (5a) and (16b) therefore constitute minimal pairs. It could of course be claimed that incorporation into $\mathrm{F}^{\circ}$ is optional in these cases, but optional movement is not permitted in a Minimalist framework. The difference between (5a) and (16b) seems to lie in the specific properties of $F^{\circ}$ in the two cases. Notice that the circumpositional construction (3) is limited to adjunct positions for most speakers. This can be shown by the contrast in (31): the complex prepositional construction is selected as an argument by a verb expressing movement in (31a), while the circumpositional construction is clearly only an adjunct in (31b).

(31) a. Chico fell down from the fifteenth floor $/ *$ from the fifteenth floor down.

b. Nice apartments can be found from the fifteenth floor down $/ *$ down from the fifteenth floor.

It seems then that overt incorporation of $\mathrm{F}^{\circ}$ into $\mathrm{P}^{\circ}$ is triggered by government of $\mathrm{F}^{\circ}$ by the matrix $\mathrm{V}^{\circ}(11)$ or another $\mathrm{P}^{\circ}$ such as from in $(30)$. The $\mathrm{F}^{\circ}$ head of adjunct PPs is not so governed and therefore does not trigger incorporation. In other words, a "directional" verb or preposition such as fall in (11) or from in (30) selects a "strong" $F^{\circ}$ morpheme which triggers overt incorporation, whereas an ungoverned $\mathrm{F}^{\circ}$ as in (3) is a "weak" $\mathrm{F}^{\circ}$ morpheme which cannot trigger incorporation of $\mathrm{P}^{\circ}$. Both "weak" and "strong" $F^{\circ} s$ can be spelled out as down.

Summarizing, we can say that there are three types of complex prepositional constructions in English which share a single syntactic structure FP - PP. In a structure such as out of the house, the $\mathrm{F}^{\circ}$ of does not incorporate out. The $\mathrm{F}^{\circ}$ of is a "strong" Case assigner, forcing movement of the NP complement of out to SpecFP in order to check Case. In a structure such as down from the top, the $\mathrm{P}^{\circ}$ from incorporates overtly into the $\mathrm{F}^{\circ}$ down. The NP complement of from moves overtly to Spec-FP to check Case in a Spec-Head configuration. Finally, in a circumpositional construction such as from the top down, no overt movement occurs at all. Thus, a "strong" overtly incorporating $\mathrm{F}^{\circ}$ is also a "strong" Case assigner, but a "strong"
Case assigner need not be a "strong" incorporating $\mathrm{F}^{\circ}$ : an example is the $\mathrm{F}^{\circ}$ of in out of the house in $(19 \mathrm{~b})$. We may conclude that English complex prepositional constructions offer good evidence for the presence of right-branching functional projections in the domain of PP.

\section{NON-SYNONOMY BETWEEN "STRONG" AND "WEAK" F'S}

Dutch resembles English and German in that it also exhibits alternations between circumpositional and complex prepositional constructions:

(32) a. Het water vloeide [van de tafel af] the water flowed from the table off (naar het midden van de kamer) (towards the middle of the room)

b. Het water vloeide [vanaf de tafel] The water flowed from-off the table * (naar het midden van de kamer) (towards the middle of the room)
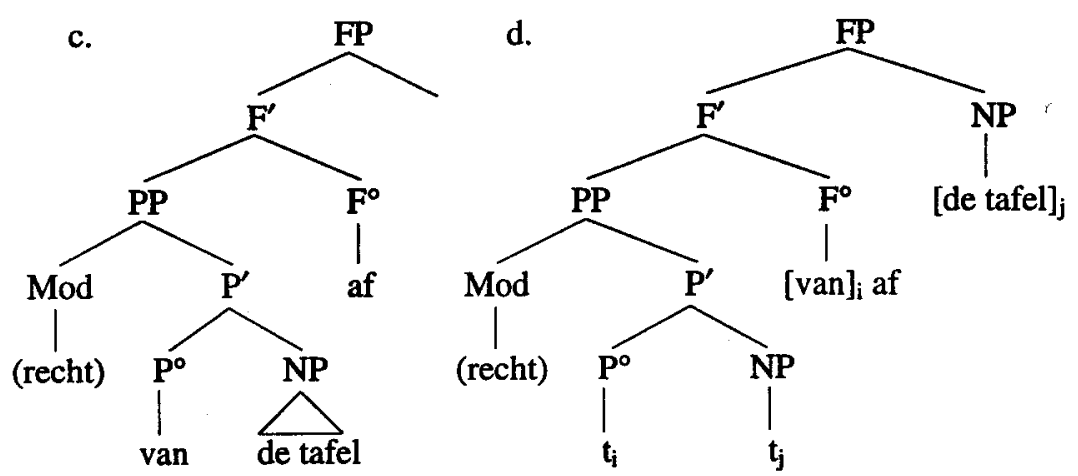

In (32), the first PP introduced by van(af) 'from(off)' is an adjunct, while the second PP, introduced by naar 'to', is selected as the directional complement of the verb. The only difference is that Dutch $\mathrm{P}^{\circ} \mathrm{s}$ incorporate to the left of $\mathrm{F}^{\circ}$ rather than to the right as in English. 16 Otherwise, the circumpositional construction (32a) has the structure of (3) and the complex prepositional construction (32b) has the structure (23). In (32b), we again have an instance of a directional verb selecting a "strong" $\mathrm{F}^{\circ}$ spelled out as af 'off' which obligatorily incorporates the preposition van 'from'. 17

There is an important meaning difference between the circumpositional and the complex prepositional construction. In (32a), the circumpositional PP refers to the Path travelled by the water. In (32b), the complex prepositional construction indicates primarily the point of origin of the water. In (32b), the water need not be 
on the table when flowing to the middle of the room, it can simply start flowing from the legs of the table. This interpretation is not available in (32a): in this case, the water starts its Path on the table. The circumpositional PP in (32a) only has a Path meaning, whereas in (32b) the vanaf phrase expresses "point of origin" of the Path, while the Path itself is expressed by the obligatory second PP. We therefore want to argue that the "strong" $\mathrm{F}^{\circ}$ which incorporates $\mathrm{P}^{\circ}$ also adds meaning to $\mathrm{P}^{\circ}$, more precisely $\mathrm{F}^{\circ}$ adds the starting point of the Path. A "weak" $\mathrm{F}^{\circ}$ does not add such meaning.

In some Dutch complex prepositional constructions, the NP precedes the complex preposition $(33 a, b)$. It would not be very insightful to claim that Spec-FP in these cases is left-branching rather than right-branching as in the structure (3a) which we adopt for (32). In fact, these constructions instantiate cases in which the NP has scrambled out of the PP. The sentences $(33 a, b)$ therefore have structures as in $(33 \mathrm{c}, \mathrm{d}): 18$

(33) a. De fles dreef de brug onderdoor/*onderdoor de brug. the bottle floated the bridge under-through/under-through the bridge

b. De fles dreef onder de brug door the bottle floated under the bridge through

c.

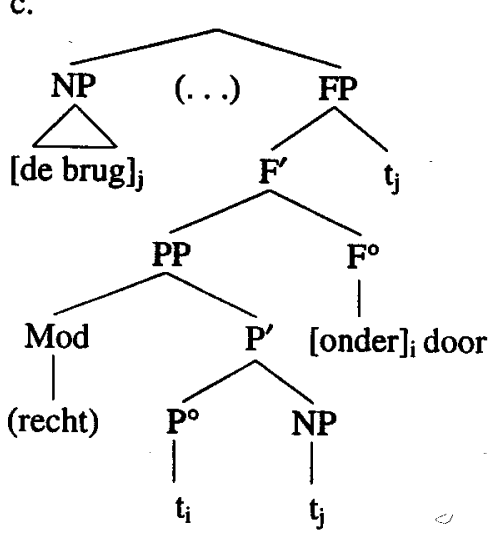

d.

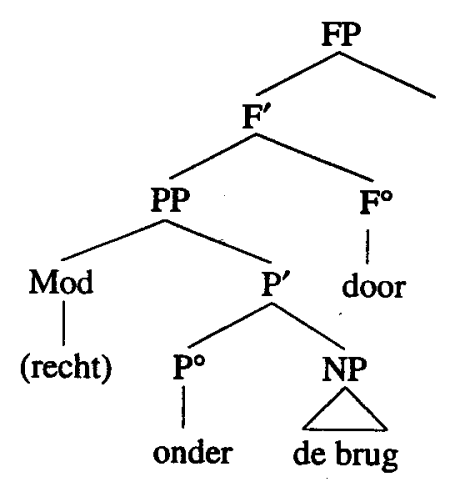

Note that the scrambled NP gets Case in Spec-FP on its way out of FP. The motivation for assuming scrambling of the NP out of the PP in $(33 a, c)$ is quite strong. Adverbs modifying the VP may intervene between the NP and the complex $\mathrm{F}^{\circ}-\mathrm{P}^{\circ}$. The position of the P modifier in (34) also shows that the NP is outside of the PP. This is not the case for other postpositions in Dutch:

(34) Vele flessen dreven de brug zonder problemen recht onderdoor many bottles floated the bridge without problems right under-through A lot of bottles floated right under the bridge without problems.

(35) De wagens reden recht de stad (*zonder problemen) in the cars drove right the city (without problems) in

In the structure (33c), the $P$ incorporates into $\mathrm{F}^{\circ}$ by adjunction to the left of $\mathrm{F}^{\circ} .{ }^{19}$ As they are represented in $(33 \mathrm{c}, \mathrm{d})$, both PP structures seem to be structural variants of the same construction. This would imply that overt incorporation of the $\mathrm{P}^{\circ}$ into $\mathrm{F}^{\circ}$, overt movement of the NP to Spec-FP position, and subsequent scrambling of this NP is an optional operation. However, in the minimalist perspective advocated by Chomsky (1993), optional movement is excluded: all movement is obligatory and motivated by morphological properties. How can the apparent optionality of movement in (33c,d) be explained? Again, the answer is that $(33 c, d)$ are not mere variants of the same construction. In fact, there is a subtle meaning difference between (33c) and (33d). Both PPs express a directional Path meaning. The meaning of (33c) however also involves a notion of erdpoint of the Path, which is altogether absent in (33d). This meaning difference is clearly revealed when a Locative $P P$ is added to $(33 a, b)$ :

(36) a. De fles dreef de brug gisteren (recht) onderdoor the bottle floated the bridge yesterday (right) under-through [in het vergaarbekken].

in the reservoir

b. De fles dreef [(recht) onder de brug door] [in het vergaarbekken] the bottlefloated (right) under the bridge through in the reservoir

In (36b), the interpretation is that the bottle floated under the bridge (Path) and then into the reservoir (Location). This interpretation is not available for (36a), in which (36a), 'the bridge' is interpreted as a specific location in the reservoir under which the bottle makes its Path. In other words, we get an interpretation similar to that of other "double" location PPs in that the first PP specifies the second, such as in a restaurant in Brussels. Therefore, we must conclude that the PP in (36a) also includes some location property. The fact that this property is the endpoint of location can be derived from the interpretation of the PP (33c) in sentences with aspectuals:

(37) a. De fles begon/??eindigde haar reis de brug onderdoor the bottle startedlfinished its trip the bridge under-through

b. De fles begon/eindigde haar reis onder de brug door the bottle startedlfinished its trip under the bridge through

In (37a), the sentence with eindigen 'finish' is not very felicitous, suggesting that the notion of endpoint of the trip is already expressed on the PP and cannot be expressed twice. 
We are now in a position to explain more precisely what happens in (33c,d). In (33c), the $\mathrm{F}^{\circ}$ has a meaning that we will characterize as "directional-towards endpoint", or "Path + endpoint". This $\mathrm{F}^{\circ}$ is a "strong" morpheme requiring overt incorporation of the $\mathrm{P}^{\circ}$ it governs, and overt Case checking of the NP selected by $\mathbf{P}^{\circ}$ before scrambling. In (33d), the $\mathrm{F}^{\circ}$ has only a Path meaning. This $\mathrm{F}^{\circ}$ is a "weak" morpheme which does not require overt incorporation nor overt NP movement to Spec-FP. The fact that $(33 \mathrm{c}, \mathrm{d})$ appear to be mere structural variants is simply due to the fact that both the "weak" and the "strong" $F^{\circ}$ are spelled out by door "through".

The $\mathrm{F}^{\circ}$ door 'through' can also remain unexpressed. In this case, there is also a difference in meaning when the NP precedes or follows the preposition onder 'under'. In postpositional constructions, the PP has only a directional "Path" meaning, on a par with (33), while the order P - NP has either a locative or a directional interpretation.

(38) a. De fles dreef de brug onder The bottle floated under the bridge.

(directional)

b. De fles dreef onder de brug The bottle floated under the bridge.
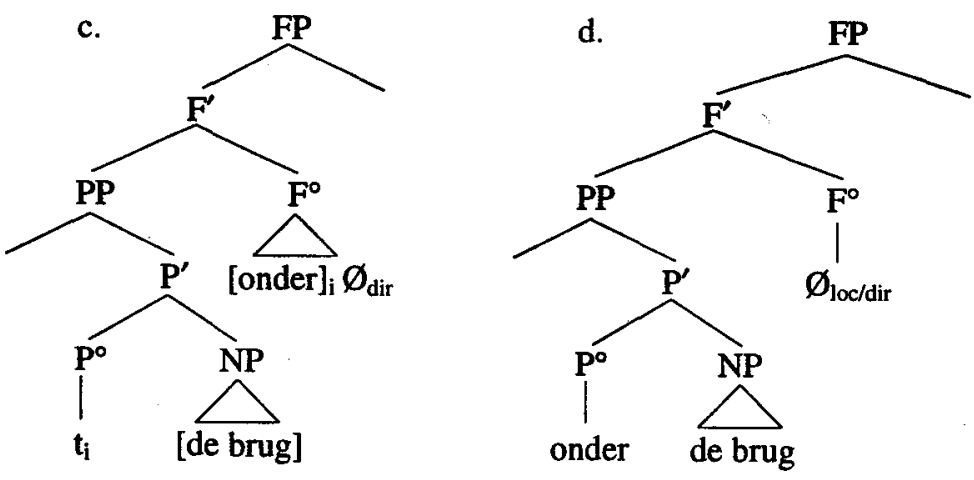

In (38a), the NP has not scrambled out of the PP: (39a) illustrates that no material can intervene between the NP and the preposition. Therefore, (38a) is on a par with (35). The position of the P modifier in (39b), which we assume to be in Spec-PP, also suggests that the NP is inside the PP:

(39) a. De flessen dreven de brug (*zonder problemen) onder the bottles floated the bridge (without problems) under

b. De flessen dreven (recht) de brug (*recht) onder the bottles floated (right) the bridge under
Notice that the structure (38c) is identical to the structure we proposed for French dessus 'under' and la-dessus 'there-under' in (23e).

As in (33), the notion "directional" is too limited to express the actual variation in meaning. In (38a), the directional meaning is accompanied by an inchoative meaning: the sentence means that the bottle has just started its Path under the bridge. Again, this "ingressive" interpretation is revealed by sentences with aspectuals:

(40) De fles begon/eindigde haar reis onder de brug /?? de brug onder the bottle startedlfinished its trip under the bridge /the bridge under

In this case, both aspectuals yield slightly awkward sentences with the NP - P construction: with beginnen 'start' because of the fact that inchoative meaning is expressed by the PP and with eindigen 'finish' because of the contradiction with the inchoative meaning.

This "inchoative-directional" $P P$ is minimally different in interpretation from the PP in (33), in which there is a "Path + endpoint" interpretation. The difference between these postpositional constructions then seems to be somewhat "aspectual" in nature, referring to beginning- and endpoints of the Path. In (38b), the directional interpretation has no such aspectual connotation.

Within the structure for Dutch PPs such as (33c,d), this meaning difference can now be explained structurally. We can say that in Dutch, a "directional-inchoative" $\mathrm{F}^{\circ}$ is a "strong" zero-morpheme which must overtly incorporate the preposition onder 'through'. This $\mathrm{F}^{\circ}$ cannot be spelled out by door 'through'. Although the preposition is incorporated into $\mathrm{F}^{\circ}$, the NP cannot move overtly to Spec-FP to check Case. Movement of NP for Case checking takes place at LF. In other words, the "directional-inchoative" $\mathrm{F}^{\circ}$ morpheme is a "strong" incorporator for $\mathrm{P}^{\circ}$, but a "weak" Case assigner for NP. Overt incorporation into $\mathrm{F}^{\circ}$ is limited to those morphemes which have "aspectual" meaning: "directional-inchoative" in (38a), "directional-towards-endpoint" in (33a,c).

The directional interpretation of (38b) has a structure identical to that of (33d), except that the directional $\mathrm{F}^{\circ}$ is not spelled out. A "purely directional" $\mathrm{F}^{\circ} \mathrm{can}$, but need not, be spelled out as door 'through'. In $(33 \mathrm{~b}, \mathrm{~d})$ and the directional interpretation of $(38 \mathrm{~b}, \mathrm{~d})$, Case checking of the NP takes place at LF.

The locative interpretation of $(38 \mathrm{~b})$ is characterized by a "weak" locative $\mathrm{F}^{\circ}$ zero-morpheme which cannot be spelled out. The structure $(38 \mathrm{~b}, \mathrm{~d})$ shows that this morpheme cannot incorporate the $\mathrm{P}^{\circ}$ onder 'under' which it governs. This morpheme does not add any meaning to the PP complex, and as a result, only the locative meaning of the preposition onder 'under' is present. The PP is spelled out without any overt movement taking place. This analysis is in line with the minimalist program, in which we expect "strong" morphemes to trigger overt movement, and "weak" morphemes not to trigger movement. There is no optional movement: specific morphemes either trigger overt movement or they do not.

Clearly, the expressed $\mathrm{F}^{\circ}$ door 'through' is what adds the directional "Path" meaning to the complex PP in (33). ${ }^{20}$ Without door 'through', and in a stative 
context, onder de brug 'under the bridge' is simply locative. In a sense, the $\mathrm{F}^{\circ}$ modalizes $\mathrm{P}^{\circ}$ in the same way a modal head such as can or might would with respect to a $\mathrm{V}^{\circ}$ : it adds a meaning to a lexical category. In addition to the modal characteristic, the overtly incorporating $\mathrm{F}^{\circ}$ morphemes in (33) and (38) have aspectual meaning, again a property typical of functional categories in the verbal domain. (41):

The analysis in (38) also applies to pre- and postpositional uses of in 'in' as in

(41) a. De fles dreef (pal) het vergaarbekken in the bottle floated (right) the reservoir into

(directional-ingressive only)

b. De fles dreef in het vergaarbekken the bottle floated in the reservoir

(locative only)

In this case, a directional $\mathrm{F}^{\circ}$ incorporates $\mathrm{P}^{\circ}$, but a locative $\mathrm{F}^{\circ}$ does not. In both cases, the NP complement of $\mathrm{P}^{\circ}$ moves to Spec-FP at LF to check Case.

The distinction between directional and nondirectional meaning is also expressed in other languages. Talmy (1985) and Carter (1988) have observed an important difference between Romance and Germanic with respect to the interpretation of PPs headed by prepositions such as under, in, and behind. Germanic languages allow for both a directional and a locative interpretation of such PPs, whereas Romance allows only for the locative interpretation (see also Emonds 1991). English (42b) has a directional interpretation which is impossible for its French counterpart $(42 a)$ :

(42) a. La bouteille flottait [sous le pont]

(locative)

b. The bottle floated [under the bridge]

(locative/directional)

In both French and English, the preposition sous/under has basically a locative, nondirectional meaning. We clearly do not want to stipulate that English under has a feature [ \pm directional] whereas French sous 'under' would be [- directional] only. ${ }^{21}$ This would just restate the problem. The locus of variation therefore cannot be the preposition itself. The difference between the two sentences of (42) cannot be attributed to a difference in directionality of the verbs flotter/float either: both are stative verbs. 22

In light of our analysis of French dessous 'under' in (23e), and of English prepositions as involving the structure (18), we are now in a position to analyze this distinction in configurational terms and relate it to the contrast between the productivity of complex prepositional constructions in English and their limited occurrence in Romance. We would like to propose that in (42b), under either incorporates into an empty $\mathrm{F}^{\circ}$ with directional meaning or into a nondirectional, locative, empty $\mathrm{F}^{\circ}$. The directional or locative character of $\mathrm{F}^{\circ}$ determines the directional or locative meaning of the PP. The existence of directional and locative $\mathrm{F}^{\circ} \mathrm{s}$ in English is independently justified. In complex prepositions in English, $\mathrm{F}^{\circ} \mathrm{can}$ add directional meaning to a locative preposition (down on the farm, out on the road), incorporating the preposition it selects, but it can also be entirely nondirectional as is of in out of the country which does not (overtly) incorporate out.

In French, however, complex directional prepositions as in English or Dutch are altogether absent. ${ }^{23}$ As we have seen, the only complex prepositional constructions involve the very limited set of locative dessous 'under' and dessus 'above'. Therefore, it is legitimate to infer that French does not have directional $\mathrm{F}^{\circ}$ morphemes, unlike English and Dutch. The difference between these languages is simply morphological: in the domain of $\mathrm{PP}$, the system of functional projections in French is not as rich as in English or Dutch. To put it differently, if directional $\mathrm{F}^{\circ} \mathrm{s}$ can be likened to modals in the prepositional domain, French simply lacks the set of motals for prepositions. This difference is morphologically apparent: in English, $\mathrm{F}^{\circ}$ can be expressed by a large set of prepositions, whereas in French, $\mathrm{F}^{\circ}$ can only be realized by the Case marker de 'of'. The non-synonomy of (42a) and (42b) can be immediately accounted for: since French has no directional $\mathrm{F}^{\circ} \mathrm{s}$, the PP in (42a) can have only the locative meaning of the preposition sous 'under'.

The analysis presented here has the advantage of deriving the meaning difference in (42) in a way that is less stipulative than lexically registering the difference as a property of prepositions. Since French lacks the set of (covert or overt) modals for prepositions that exist in Dutch and English, the directional meaning cannot be derived for the FP - PP complex. Instead of stipulating a lexical property of prepositions, we only have to stipulate the absence of a specific set of functional projections. This should be hardly surprising: crosslinguistic variation in the range of meanings expressed by functional projections is quite common.

There are some additional facts of Dutch PP syntax which can be explained by the approach adopted here. Van Riemsdijk (1978) notes that postpositions in Dutch can be stranded freely, whereas prepositions can be stranded only with pronouns of a specific morphological type, so-called R-pronouns such as waar 'where' or er 'there' (cf. note 19). The effects of this constraint can be observed in (43): the directional interpretation accommodates both waar 'where' and dat/die 'that', but the locative interpretation is compatible only with waar 'where' as a relative marker. In other words, the directional interpretation of (43) corresponds to the postpositional structure in (41a) and the locative interpretation of (43a) corresponds to the prepositional structure in $(41 b)$. The same is true for $(44 a, b)$, where the meaning correspondence to $(38 \mathrm{a}, \mathrm{c})$ and $(33 \mathrm{a}, \mathrm{c})$, respectively, clearly indicates that the relativizing empty NP operator has moved from a position preceding $\mathrm{P}^{\circ}$.

(43) a. Dit is het vergaarbekken waar ${ }_{i}$ de fles [in $t_{i} / t_{i}$ in] dreef this is the reservoir wherelthat the bottle in floated This is the reservoir into/in which the bottle floated.

(locative/directional) 
b. Dit is het vergaarbekken dat; de fles [ $t_{i}$ in] dreef This is the reservoir where/that the bottle in floated This is the reservoir into which the bottle floated.

(44) a. Dit is de brug die de fles $t_{i}$ onder dreef this is the bridge that the bottle under floated

(cf. (38a,c), ingressive only)

b. Dit is de brug die de fles $t_{i}$ onderdoor dreef this is the bridge that the bottle under-through floated

(cf. (33a,c), endpoint only)

In the framework adopted here, Van Riemsdijk's (1978) observation concerning the free stranding of postpositions must be reformulated. We have seen that postpositions do not constitute a homogeneous syntactic class: the contrast between (34) and (39) shows that complex postpositions such as (33a,c) allow their.NP to scramble into the clause, whereas in the postpositions in $(38 \mathrm{a}, \mathrm{c})$ the NP is still in its base position. Why would these different syntactic types of postpositions behave alike with respect to NP movement out of them?

In the framework developed here, preposition stranding seems to be freely possible in Dutch only with "strong" $\mathrm{F}^{\circ} \mathrm{s}$ incorporating $\mathrm{P}^{\circ}$. The "R-pronoun" constraint applies only when no incorporation occurs as in circumpositions $(33 \mathrm{~b}, \mathrm{~d})$ and in cases where both NP and $\mathrm{P}^{\circ}$ stay down in their PP as in (38b,d).24 "Free" preposition stranding of postpositions basically means that the NP complements can move out of the PP. In this case, NP complements of postpositional $\mathrm{P}^{\circ} \mathrm{s}$ behave syntactically in the same way as NP arguments of $\mathrm{V}^{\circ}$ in the sense that they can be $A^{\prime}$ moved and relativized by non-R-pronouns. Van Riemsdijk's (1978) generalization then can be reformulated by saying that NP complements of $\mathrm{P}^{\circ}$ behave like NPs which are VP arguments only when $\mathrm{P}^{\circ}$ incorporates into $\mathrm{F}^{\circ}$. This generalization applies regardless of whether the NP itself is in P' or whether it has scrambled out of the FP - PP complex.

Why would $\mathrm{P}^{\circ}$ to $\mathrm{F}^{\circ}$ incorporation make the NP complements of $\mathrm{P}^{\circ}$ behave like regular VP complements? The answer can be found in Guéron and Hoekstra's (1988) idea of T-chains. Moving the $\mathrm{P}^{\circ}$ up to $\mathrm{F}^{\circ}$ means that the $\mathrm{P}^{\circ}-\mathrm{F}^{\circ}$ complex is governed by the $\mathrm{V}^{\circ}-\mathrm{T}^{\circ}-\mathrm{Agr}^{\circ}$ complex, which in this way can extend its domain all the way into the PP. In other words, moving the $\mathrm{P}^{\circ}$ up to $\mathrm{F}^{\circ}$ brings the PP closer to the T-chain of the matrix verb. This domain extension of the verb into the PP then entails that NP complements of $\mathrm{P}^{\circ}$ can behave in the same way as any NP argument of $\mathrm{V}^{\circ}$ with respect to movement. When a $\mathrm{P}^{\circ}$ does not move up to $\mathrm{F}^{\circ}$, no such domain extension of the verb is possible, and only $\mathrm{R}$-pronouns are allowed to move out of the FP - PP complex. ${ }^{25}$ If this explanation is on the right track, we have an additional argument for the analysis of the structure $(38 \mathrm{~b}, \mathrm{~d})$ without movement of $\mathrm{P}^{\circ}$ to $\mathrm{F}^{\circ}$.

\section{CONCLUSION}

The analysis developed here shows that there is good evidence for reformulating prepositional Case marking in strict $\mathrm{X}$ bar theoretic terms as a Spec-Head relation. In keeping with the minimalist assumptions suggested by Chomsky (1993), all structural Case marking can be reduced to Spec-Head agreement within a functional projection. Complex prepositional constructions such as out of the house, and down on the farm constitute good evidence for head-final FPs. Circumpositional constructions in German, Dutch and English further corroborate the PP - FP structure proposed. The productivity of multiple prepositions in English can be accounted for in terms of incorporation, which explains the restrictions on the occurrence of $\mathbf{P}$ modifiers. English differs from a language such as French in that "true" prepositions can spell out $\mathrm{F}^{\circ}$, whereas in French, only Case markers can spell out $\mathrm{F}^{\circ}$. This admittedly descriptive difference between French and English can account for some important differences in the interpretation of locative PPs in both languages.

\section{NOTES}

- I would like to thank Teun Hoekstra, Sarah Jourdain, Pierre Pica, Jaume Solà, Laurie Zaring, and two anonymous reviewers of this volume for comments and discussion. Also thanks to audiences at the Université du Québec à Montréal, the University of Groningen, the Rightward Movement conference at Tilburg University and the Comparative Germanic Syntax Workshop at Harvard. Special thanks go to Marcel den Dikken for extensive comments on previous versions of this paper. The usual disclaimers apply.

1 Van Riemsdijk (1990) argues that the structure in (3a) is motivated by Case and selection. The selectional properties of ( $3 a$ ) show that the first preposition exercises selectional restrictions on the following NP. Van Riemsdijk (1990) also argues that this preposition determines the Case of the NP: unter 'under' assigns dative Case, whereas $d u r c h$, as a preposition, only selects accusative. Van Riemsdijk (1990) therefore concludes that dative Case is directly assigned to the NP complement of $\mathrm{P}^{\circ}$ in (3a). In the approach adopted here, however, we want to maintain the idea that Case is assigned in SpecFP as a function of the Spec-Head relation. Therefore, we assume that there is an important difference ( between durch 'th 'through' does not function as a $\mathrm{P}^{\circ}$ associated with an accusative Case (an $\mathrm{F}^{\circ}$ ) of its own. More specifically, we propose that the FP of unter 'under' assigns dative Case, and that the $\mathrm{F}^{\circ}$ selecting the PP headed by unter 'under' can be spelled out as durch 'through'. As an $\mathrm{F}^{\circ}$, durch 'through' loses both its selectional properties and its corresponding accusative Case projection. In (3a), the dative NP is checked in the Spec-FP of durch 'through' at LF. This does not mean that there are two homonyms durch 'through'. We must simply say that prepositions can function either as lexical elements or as functional elements. This is not surprising in view of the fact that prepositions are the only lexical category which constitutes a "closed class".

2 In Dutch, circumpositional constructions are found in argument positions:

(i) De boot laveerde (pal) onder de brug ( ${ }^{*}$ pal) door the boat navigated (straight) under the bridge (*straight) through

3 One reviewer asks how sentences such as (i-ii) would be represented in the analysis advocated here:

(i) Decisions were communicated from the top all the way/right on down 
(ii) Nice apartments can be found from the third floor all the way/right on up

Unlike the P modifiers straight and right, all the way and right on can occur in front of $u p$ and down, modifying them. At first sight, this contradicts our analysis of up and down as functional elements in circumpositions such as (i-ii) which cannot be modified. In the analysis advocated here, all the way and right on can be considered PP adjuncts generated between PP and the right-branching FP:

(iii) [FP [PP [PP from the top] all the way/right on ] down ]

The adjuncts all the way and right on modify the PP from the top, indicating the Path between from the top and the directional $\mathrm{F}^{\circ}$ down. These adjuncts can also be generated to the left of PP:

(iv) [FP [PP All the way [PP from the top] down ]

4 This is not to say that Ps cannot select PPs. In those cases where P modifiers such as right, straight do occur between prepositions, we clearly have a case of a P selecting another PP:

(i) He jumped from (right) behind the door.

(ii) He jumped (right) from behind the door

5 This analysis might be corroborated by the fact that the second PP cannot be fronted leaving the first one stranded:

(i) * Onto the table fell Harpo down the stairs

It is usually the case that adjuncts cannot be stranded when the constituent they modify is fronted:

(ii) Eat an apple, I think they often will.

(iii) *Eat an apple, I think they will often.

(iv) Often eat an apple, I think they will.

(v) Grace gave the red book with Japanese prints to Marg.

(vi) *'The red book, Grace gave with Japanese prints to Marg.

(vii) *The red book, Grace gave to Marg with Japanese prints.

(viii) A red book was given to Marg with Japanese prints.

6 This is true regardless of whether straight and right occur in Spec-PP or constitute an independent functional projection selecting PPs. See Den Dikken 1992: 108 for an analysis along these lines.

7 It could be argued that since up selects a Path NP, it also selects the Path PP to the attic in (19) However, this analysis cannot explain sentences such as Ellen had water up to her nose, where to her nose does not express a Path by any definition, but rather an Endpoint. The $F^{\circ}$ up here modifies the Endpoint to her nose by specifying the Path preceding the Endpoint.

8 This is where the parallelism stops. Unlike prepositional FPs, which cannot be modified by the P modifiers right, straight, the functional categories in the verbal domain can take modifiers such as just as in Tony just might do that.

9 I will not analyze verb-particle constructions of the following type: (i) John put the books down on the table.

Den Dikken (1992) points out that in (i) the object NP or adverbs such as quickly can separate particle and PP:

(ii) John put down the books on the table.

(iii) John put the books down quickly on the table.

Moreover, Locative Inversion applies separately to the PP following the particle:

(iv) On the shelf were put down three books.

In these cases, I would like to argue that the particle down is not an $\mathrm{F}^{\circ}$ incorporated by on. See den Dikken (1992) for a small clause analysis of these particle constructions. It seems that PPs embedded in particle constructions can themselves select FPs and incorporate their heads:

(*) John put back the books down (*quickly/right) on the shelf

Note also that the examples (16-19) cannot be analyzed as verb-particle constructions.

10 Or to be more precise, $\mathrm{AgrS}^{\circ}$ selects a $\mathrm{TP}$, and $\mathrm{AgrO}^{\circ}$ either AspP or VP.

11 Thanks to Marcel den Dikken for pointing out the relevance of these facts to me. See also den Dikken 1992: §2.4.4.2.

12 I owe this observation to Jaume Solà.

13 The morphological complexity of au-dessus 'over', en-dessous 'under' is due to a diachronic process where the $\mathrm{F}^{\circ}-\mathrm{P}^{\circ}$ complex dessus/dessous was first reanalyzed as a noun, whence the presence of au (=Preposition + determiner) and the preposition en. The constituents au-dessus 'over', en-dessous 'under' were then again reanalyzed as complex prepositions, in the same way as autour 'around'. Synchronically, they are to be analyzed as single prepositions because of the fact that they take prepositional modifiers such as juste 'right' and droit 'straight'. The Case marker de 'of' is not part of the complex $\mathrm{P}^{\circ}$ since it can be left unexpressed when the prepositions are not followed by a full NP ( $J e$ l'ai mis en-dessous/au-dessus 'I put it underneath/on top').

14 In some varieties of French (Prince Edward Island, King \& Roberge 1990: (37a,b)), the complex preposition dedans 'in' licenses a Wh- trace:
(i) L'avion a crashé dans la grange. The plane crashed in the hangar.
(ii.) Quoi-ce que l'avion a crashé dedans $\mathbf{t}$ ? What did the plane crash in?

The equivalent of (ii) is ungrammatical in Standard French (Zribi-Hertz 1984).

Sportiche's (1990) arguments for treating là 'there' and $i c i$ 'here' as NPs are based on the fact that they behave as NPs with respect to Principle $C$ of the Binding Theory. Another argument for their NP status comes from the fact that $l a ̀$ 'there' cannot be modified by prepositional modifiers such as droi 'right' while directional PPs in this environment can be:

(ii) Louise allait toujours (droit) au restaurant/(*droit) lì Louise always went (right) to the restaurant/(right) there.

Also, ici 'here' and là 'there' can be used as subjects, whereas PPs cannot (Modern French lacks Locative Inversion):

(iii) Ici/Là /*Au restaurant serait un bon endroit. Here/there/in the restaurant would be a good spot. 
15 See Sportiche 1992 for an exploration of similar effects in other functional projections.

16 Alternatively, it might of course be that the preposition in Dutch does not incorporate at all, also yielding the surface order $\mathrm{P}^{\circ}-\mathrm{F}^{\circ}-\mathrm{NP}$. However, the fact that the $\mathrm{P}^{\circ}-\mathrm{F}^{\circ}$ complex constitutes a strong intonational unit, with the $\mathrm{F}^{\circ}$ bearing the accent (unlike English out ofloutta) might be taken as evidence for incorporation.

17 Dutch also has the following circumpositions and complex prepositions:

(i) De dolfijn pakte de bal onder de doos uit/onderuit de doos. the dolphin took the ball under the box out/under-out the box

However, the circumpositional and complex prepositional construction do not have the same underlying structure. Recall $\mathrm{F}^{\mathbf{o}} \mathbf{s}$ do not select NP: they lose the selectional restrictions they have as $\mathbf{P}^{\mathbf{o}} \mathbf{s}$ when functioning as $\mathrm{F}^{\circ} \mathrm{s}$ (cf. down from the tableffrom the table/*down the table). The circumpositional construction in (i) is parallel to (ii), and the complex PP is parallel to (iii).

(ii) De dolfijn pakte de bal onder de doos. the dolphin took the ball under the box

(iii) De dolfijn pakte de bal uit de doos the dolphin took the ball out of the box

This shows that in the circumpositional construction of (i) onder 'under' selects the NP and uit 'out' is the "weak" $\mathrm{F}^{\circ}$, while in the complex prepositional construction the $\mathrm{P}^{\circ}$ uit 'out' incorporates into the "strong" $\mathrm{F}^{\circ}$ onder 'under', as is evident from the fact that $\mathrm{P}^{\circ}$ modifiers cannot intervene between onder 'under' and uit 'out' in (i).

A similar problem affects the following alternation:

(iv) De bloempot viel vanuit het raam $l^{*}$ van het raam uit the flowerpot fell from-out the window / from the window out

(v) Kobus kon de bloempot zien van het raam uit Kobus could the flowerpot see from the window out

There is no straightforward relation between the circumpositional and complex prepositional constructions here either. In (iv), the preposition selecting the NP is uit 'out', not van 'from', since van 'from' cannot select the NP het raam 'the window' on its own:

(vi) De bloempot viel ${ }^{*}$ van/ uit het raam the flowerpot fell from/ out of the window

In (v), the preposition selecting the NP het raam 'the window' is clearly van 'from': (v) is synonomous to (vii), (Kobus is near the window), while (viii) is out.

(vii) Kobus kon de bloempot zien van zijn raam. Kobus could see the flowerpot from his window.

(Southern Dutch)

(viii) * Kobus kon de bloempot zien uit zijn raam.

Kobus could see the flowerpot outside of his window.

Since the thematic restrictions are determined by different elements in (iv) and (v), these constructions are not to be derived from the same structure despite their apparent similarity. Note that the selecting preposition uit 'out' in the complex PP in (i) is to the right of van 'from', not to the left as in the case
(32-33) where the order $\mathrm{P}^{\circ}-\mathrm{F}^{\circ}$ results from incorporation of $\mathrm{P}^{\circ}$ to the left of $\mathrm{F}^{\circ}$. We must therefore conclude that vanuit 'from-out' is a single complex $\mathrm{P}^{\circ}$. The same analysis applies to complex prepositions such as onderaan 'under by':

(viii) Ze vond dat boek [vlak onderaan de trap $\left[/ *\right.$ [onder vlak aan de trap] $/^{*}$ [onder de trap aan] She found the book right (down) under by the stairs.

Unlike in the complex preposition vanaf 'from-of' in (32), where the $\mathrm{P}^{\circ}$ van 'from' selects the NP, in onderaan 'under by' it is aan 'on' that selects the NP, in the same way as uit 'out' in vanuit 'from-out' in (iv). We therefore assume that onderaan 'under by' and vanuit 'from-out' are single complex $\mathrm{P}^{\circ} \mathrm{s}$. These complex $\mathrm{P}^{\circ} \mathrm{S}$ do not arise from syntactic incorporation, but from (right-headed) lexical composition.

18 It should be noted that there is some variety as to the acceptability of examples such as (32) and (38). Sentences such as (32a) are often considered ungrammatical by speakers of Northern varieties of Dutch while they are perfect for people speaking Southern varieties of Dutch, both in Belgium and in the Dutch province of Brabant.

19 Structures such as $(33 \mathrm{a}, \mathrm{c})$ with scrambling of the NP out of the PP are quite restricted and occur with few prepositions:

(i) achter het huis langs behind the house past passing behind the house

(ii) het huis achterlangs the house brhind-past passing behind the house

(Marcel den Dikken, p.c.)

In some cases, overt movement to Spec-FP and subsequent scrambling out of the PP domain simply does not apply to full NPs (iv), and is restricted to expletive NPs as in (v). The adverb between er 'there' and the complex preposition in (v) shows that $e r$ 'there' scrambles out of the FP.

(iii) Ze gleden [naar de brug toe]/[van de brug af]/[tegen de muur aan] they slid towards the bridge tol from the bridge of / against the wall at

(iv) * Ze gleden [de brug naartoe]/ [debrug vanaf]/ [de muur tegenaan] they slid the bridge towards-tol the bridge from-of I the wall against-at

(v) $\mathrm{Ze}$ gleden er langzaam [naartoe]/ [vanaf]/ [tegenaan] they slid there slowly towards-to/from-of / against-at

20 It should be stressed that the preposition door 'through' does not exercise any selectional restriction on the NP the bridge in (33). As a preposition, door 'through' clearly could not select an NP such as the bridge without special meaning effects identical to those in *?through the bridge. In the cases at hand door 'through' adds meaning to the PP without selecting the NP. The added directional (Path) meaning in (33) does not depend on the main verb drijven 'float': in a sentence such as Ze waren de brug onderdoor, lit. 'They were the bridge under-through', the directional (Path) meaning is present despite the stative verb zijn 'be'. Something similar is true for English complex prepositions as in They lived down on the farm, where a slight Path connotation is also present in the PP despite the stative characte of the entire sentence.

21 Hoekstra (1988) suggests that the nondirectional meaning of (42a) should be related to the fact that French does not have resultatives such as John ran the carpet thin. French then would not have eithe PP or AP resultatives of the relevant type. However, I am informed by Ruth King and Yves Roberge that 
contrary to Standard French, Prince Edward Island French does have a directional (resultative) interpretation for the sentence (42a). Nevertheless, PEI French does not allow for the counterpart of resultatives such as John ran the carpet thin, which are uniformly excluded. As a result, the absence of a directional interpretation for (42a) cannot be related to a more general restriction on the occurrence of resultatives in French.

22 Of course a PP such as sous le pont 'under the bridge' in French can receive a directional interpretation in the context of a directional, nonstative verb such as aller $\mathrm{go}^{\prime}$ :

(i) Il allait sous le pont.

He went under the bridge.

In this case, the directional interpretation is a function of the directional verb aller 'go', and not of the PP. The point made in (42) is that directionality in this case cannot be influenced by factors having to do with the meaning of the verb.

Betsy Klipple points out to me that there might be a difference between French and English flotter/ float, since flotter 'float' does not allow for directional PPs whereas float does:

(ii) ?* La bouteille flottait vers le pont

(iii) The bottle floated towards the bridge

However, under the analysis presented here, this difference can again be related to the fact that English has directional $\mathrm{F}^{\circ} \mathrm{s}$ while French does not. The FPs in (ii-iii) arguably are not arguments of flotterffloat, but rather adjuncts. Since the PP is an adjunct in (ii-iii), flotter/float does not properly govern $\mathrm{F}^{\circ}$ and hence does not exercise selectional restrictions on the head $\mathrm{F}^{\circ}$ of FP. Since English has both directional and locative $\mathrm{F}^{\circ}$ s, directional and locative adjuncts can appear with float. French having only locative $\mathrm{F}^{\circ} \mathrm{s}$, these appear by default in FP adjuncts, and thus exclude the selection of a directional PP in (ii). In (i), however, the $\mathrm{PP}$ is an argument, and as a result its $\mathrm{F}^{\circ}$ can be subject to proper government and selection by the directional verb aller ' $\mathrm{go}$ '.

23 This claim might seem too strong in light of the fact that French has complex prepositional structures such as par-dessus 'over', par-dessous 'under' (directional), de dessous 'from beneath'. At first sight, these look like complex $\mathrm{F}^{\circ}-\mathrm{P}^{\circ}$ structures of the type analyzed here for English and Dutch: no ${ }^{\circ}$ modifiers can appear between the two prepositions, in the same way as in (16-19):

(i) Le voleur a sauté [pp (juste) par- (*juste) dessus le mur]

The thief jumped (right) over the wall.

(ii) L'archéologue l'a tiré [pp (droit) de (*droit) dessous les rochers] The archeologist has pulled it (right) from underneath the rocks.

However, these constructions fail the selection test we have used to determine the status of complex prepositional structures as syntactically formed $\mathrm{F}^{\circ}-\mathrm{P}^{\circ}$ complexes. Recall that in structures such as down to, up to, it was shown that as $\mathrm{F}^{\circ} \mathrm{s}$, down and up do not exercise their thematic Path restriction which they have as $\mathrm{P}^{\circ} \mathrm{S}$ (cf. the discussion in 2.2 of down from the top/ ${ }^{*}$ down the top/from the top). We concluded that in $\mathrm{F}^{\circ}$ - $\mathrm{P}^{\circ}$ complexes, only the preposition thematically selects the NP, while the $\mathrm{F}^{\circ}$ simply adds meaning to the $\mathrm{P}^{\circ}$.

In the French complex prepositional constructions in (i-ii), neither prepositional element of each complex can be shown to do the thematic selection of NP by itself. When each $\mathrm{P}^{\circ}$ of the complex selects an NP alone, the result is either ungrammatical or has a thematic meaning different from the complex prepositional construction in (i-ii):

(iii) * Le voleur a sauté par le mur.

The thief jumped by the wall. (iv) Le voleur a sauté sur/*dessus le mur.

The thief jumped on the wail.

(v) L'archéologue l'a tiré des rochers. The archeologist has pulled it out of the rocks.

(vi) L'archéologue l'a tiré sous $/{ }^{*}$ dessous les rochers. The archeologist has pulled it under the rocks.

Such a strong thematic difference never appears in English and Dutch $\mathrm{F}^{\circ}-\mathrm{P}^{\circ}$ constructions: the complex down from the top and the simplex from the top both express the thematic role Origin, showing that the directional $\mathrm{F}^{\circ}$, expressed as down or as a zero-morpheme, does not intervene in selection of the $\mathrm{NP}$ complement of $\mathrm{P}^{\circ}$. We have to conclude that French complex prepositional structures are complex $\mathrm{P}^{\circ}$ formed in the lexicon by composition. This accounts for their compositional meaning and the fact that they together select the Path (par-dessus 'over') or Location-of-origin (de dessous 'from underneath') of the NP in (i-ii). The presence of the $F^{\circ}$ de inside the $\mathrm{P}^{\circ}$ compound can be related to the presence of de in semantically transparent nominal compounds such as carnet de chèques 'checkbook'.

24 In cases such as (32b) where the $\mathrm{P}^{\circ}$ van 'from' overtly incorporates into the $\mathrm{F}^{\circ}$ af 'off' and the $\mathrm{NP}$ overtly moves to Spec-FP, no NP movement out of the FP-PP complex is possible, not even with Rpronouns. The sentence (i), with an R- pronoun, has a meaning that corresponds only to that of the circumpositional construction in (32a), with the water flowing from the top of the table:

(i) Dit is de tafel waar $r_{j}$ het water van $t_{i}$ af vloeide naar het midden van de kamer this is the table where the water from off flowed to the middle of the room

This is due to the fact that contrary to (32a), the vanaf $N P$ complement is an adjunct in (32b) and constitutes an adjunct island for extraction. This means that it is impossible to check whether constructions where both $\mathrm{P}^{\circ}$-to- $\mathrm{F}^{\circ}$ incorporation and NP-movement to Spec-FP are overt also allow for preposition stranding, as would be predicted by the reformulation of Van Riemsdijk's (1978) observation which we adopt here.

29 The exceptional behavior of $\mathrm{R}$ - pronouns can be linked to Case. $\mathrm{R}$ - pronouns can be viewed as nominal expletives which spell out Case as a morphological $R$ - property which must be checked in SpecFP. This means they are the only NP elements that must move overtly to Spec-FP to check Case before scrambling out of the FP. See note 19 for other examples.

\section{REFERENCES}

Carter, Richard: 1988, On Linking: Papers by Richard Carter, Lexicon Project Working Papers 25 MIT, Cambridge.

Chomsky, Noam: 1986, Barriers, MIT Press, Cambridge.

Chomsky, Noam: 1993, 'A Minimalist Program for Linguistic Theory', in Kenneth Hale and Samuel J. Keyser (eds.), The View from Building 20. Essays in Linguistics in Honor of Sylvain Bromberger, MIT Press, Cambridge, pp. 1-52.

den Dikken, Marcel: 1992, Particles, Ph.D. dissertation, Leiden University (published as Particles: On the Syntax of Verb-Particle Triadic and Causative Constructions, Oxford University Press, New York, 1995).

Emonds, Joseph: 1986, 'Les parties du discours en grammaire générative', in Pierre Pica (ed.) Recherches linguistiques de Vincennes 14-15, Université de Paris VII, Vincennes, pp. 93-154.

Emonds, Joseph: 1991, 'Subcategorization and Syntax-based Theta-role Assignment', Natural Language and Linguistic Theory 9, 2-54.

Guéron, Jacqueline and Teun Hoekstra:1988, 'T-Chains and the Constituent Structure of Auxiliaries', 
in Anna Cardinaletti, Guglielmo Cinque, \& Giuliana Giusti (eds.), Constituent Structure. Papers from the 1987 GLOW Conference, Foris, Dordrecht, pp. 35-101.

Guerssel, Mohand: 1991, On the Case System of Berber, ms., UQAM, Montreal.

Haase, Alfons: 1914, Syntaxe française du XVIle siècle, Delagrave, Paris.

Hendrick, Randall: 1976, 'Prepositions and X' theory', in Joseph Emonds (ed.), Proposals for Semantic and Syntactic Theory: UCLA Papers in Syntax 7, pp. 95-122.

Hoekstra, Teun: 1988, 'Small Clause Results', Lingua 74, 101-139.

Hoekstra, Teun \& René Mulder: 1990, 'Unergatives as Copular Verbs', The Linguistic Review 7, 1-79. Jackendoff, Ray: 1973, 'The Base Rules for Prepositional Phrases', in Stephen Anderson \& Paul Kiparsky, (eds.), A Festschriftfor Morris Halle, Holt, Rinehart \& Winston, New York, pp. 345-356. Kayne, Richard: 1975, French Syntax, MIT Press, Cambridge.

Kayne, Richard: 1989, 'Notes on English Agreement', CIEFL Bulletin 1, 41-67.

King, Ruth \& Yves Roberge: 1990, 'Preposition Stranding in Prince Edward Island French', Probus 3, 351-369.

Rooryck, Johan: 1994, 'On 0- and $\alpha$ - Underspecification in Syntax and Phonology', in Heidi Harley \& Colin Phillips (eds.), The Morphology-Syntax Connection, MIT Working Papers in Linguistics 22, 197-216.

Rouveret, Alain: 1991, 'Functional Categories and Agreement', The Linguistic Review 8, 353-387.

Sportiche, Dominique: 1990, Movement, Agreement and Case, ms., UCLA.

Sportiche, Dominique: 1992, Clitic Constructions, ms., UCLA.

Talmy, Leonard: 1985, 'Lexicalization Patterns: Semantic Structure in Lexical Forms', in Timothy Shopen (ed.), Language Typology and Syntactic Description, vol. 3, Cambridge University Press, Cambridge, pp. 130-176.

Tremblay, Mireille \& Ouddia Kabhaj: 1990, 'The Internal Structure of PPs in Amharic', in Jean Hutchison \& Victor Manfredi (eds.), Current Approaches to African Linguistics 7, Foris, Dordrecht, pp. 167-78.

Vanden Wyngaerd, Guido: 1994, PRO-legomena. An Investigation into the Distribution and the Referential Properties of the Empty Category PRO, Mouton de Gruyter, Berlin.

Van Riemsdijk, Henk: 1978, A Case Study in Syntactic Markedness, Foris, Dordrecht.

Van Riemsdijk, Henk: 1990, 'Circumpositions', in Harm Pinkster and Inge Genee (eds.), Unity in Diversity. Papers Presented to Simon Dik on his 50th Birthday, Foris, Dordrecht, pp. 229-241.

Vergnaud, Jean-Roger: 1974, French Relative Clauses, Ph.D. dissertation, MIT.

Zaring, Laurie: 1991, 'On Prepositions and Case-Marking in French', Canadian Journal of Linguistics 36, 363-377.

Zribi-Hertz, Anne: 1984, 'Prépositions orphelines et pronoms nuls', Recherches linguistiques 12, 46-91.

\section{N-FEATURE CHECKING IN GERMANIC VERB SECOND CONFIGURATIONS}

\section{O. INTRODUCTION}

In the tradition of generative syntax, we are accustomed to thinking of morphosyntactic licensing as specifier-head agreement. The specifier-head relation has the well-known properties of locality and uniqueness. Thus, as (1) shows, no element may intervene between a head and a phrase which entertain a specifierheat agreement relation (assuming that did in (1) occupies the head of the functional projection of the wh-features, CP): ${ }^{1}$

\section{(1) Who (*yesterday) did Bill kiss?}

Likewise, a given functional head cannot agree with two specifiers at the same time (cf. Hoekstra 1991): ${ }^{2}$

(2) *When who did Bill kiss?

If Kayne (1994) is correct, the specifier-head relation also has the property of left right directionality, with the specifier universally preceding the head in linearized structure.

In this paper, I will address the question of whether the specifier-head relation is a primitive of the grammar, or can be derived from the interaction of more basic grammatical relations.

\section{SISTERHOOD AND MOTHERHOOD}

Assuming that syntactic tree structure representations are binary branching, the properties of locality and uniqueness also apply to the thematic licensing relation between a head and its complement. In the framework of Chomsky 1993, this follows from the mechanism of Generalized Transformation, a bottom-up procedure for constructing syntactic tree representations in which no more than two phrases are combined at a time. Assuming that the tree building process is initially guided by thematic requirements, it follows that a head is first combined with one (and only one) complement. This derives the properties of locality and uniqueness. Again, if Kayne (1994) is correct, the head-complement relation also expresses a left-right directionality in linearized structure. 